ynchronous eruption presenting all the characters of modified small-pox. The elder child died, bat the infant wecovered without a bad symptom. Mr. Collinson's letter in "THE LANCET of April 9th impressed me deeply and painfully, but on reflection his cases seem to me to bear another interpretation and one of serious importance at the present juncture.

When the Stockwell Fever Hospital was first opened during the epidemic of 1870-71 for the reception of small-pox patients I acted as assistant medical officer for six months. Many hundreds were admitted during that period, but the only cases that showed evidence of recent vaccination were a series of four or five which all presented excellent cicatrices and had all been vaccinated by the same practitioner with lymph taken from revaccinations. They were the subject of a short paper in THE LANCET by the medical superintendent, the late Dr. J. B. Barbour, who took occasion to point out the worthlessness of this lymph, though the visible results of its inoculation counterfeited the genuine article. Mr. Collinson's cases seem on a par with the above and read in this light would constitute a grave indictment of the glycerinated calf lymph. A careful perusal of his startling list convinces me that all these vaccinations and revaccinations were impotent though "successful," and, indeed, his last quoted case, which he regards as anomalous, may, I think, be taken as the key to the series.

April 20th, 1ع98

I am, Sirs. yours faithfully, William Molaurin.

\section{THE ROYAL COLLEGE OF SURGEONS IN} IRELAND AND THE REFORM OF THE ARMY MEDICAL SERVICE.

To the Editors of THE LANOET.

SIRS, - I am directed to inform you that the enclosed letter has been sent by the President of the Royal College of Surgeons in Ireland to the Secretary of State for War.

I am, Sirs, yours faithfully.

ROBERT H. WOODS, F.R.C.S. Irel, Dublin, April 26th, 1898

Secretary of Council, Royal Ccllege of Surgeons in Ireland.

[ENCLOSURE.]

Royal College of Surgeons in Ireland, Dublin, April 19th, 1898. MY LORD MARQUIS, - In reference to the Army Medical Departmen and the reforms in it which are about to be carried out a rumour is current that it is intended to give no higher rank and title than that of colonel. I am unable, of course, to say what justification there may be ror such a report, but as President of the Royal College of Surgeons in freland it is my duty to state that such a decision would create much disappointment. My College has loyally acceded to your lordship's request that I should nominate two civil surgeons to do duty in the present emergency. It was led to this by the sympathy which your cardship has expressed and by your manifest desire to remove the will continue if the ordinary accepted titles are not conferred upon the will continue if the ordinary accepted titles are not conferred upon the higher ranks of the service. It ls almost unnecessary to repeat that the medical oflcers have never thought of commanding in the field, and that any suggestion of that sort is quite groundless. I beg your lordship to believe that in thus addressing you I only wish to help in speedily removieg the difficulties which exist and which prevent the filling of vacandes in the Army Medical Department.

I have the honour to be, your Lordship's obedient servant

To the Right Hon. the Marquis of Lansdowne, K.G. Secretary of State for War.

\section{THE QUEEN REGENT OF SPAIN,}

\section{To the Editors of THE LANCET.}

SIRS,-In the full and excellent account of the Ninth International Congress of Hygiene and Demography, published in THE LANCET of April 23rd, the paragraph relating to the reception of the members of the Congress at the Royal Palace at Madrid is of special interest just now. May I venture, therefore, to supplement your correspondent's notes by stating that the Queen Regent, whose wonderful courage and powers of head and heart are exciting the admiration of everyone, spoke most sympathetically and kindly of our sick and wounded soldiers and of the interest ahe took in the Queen's visit to them at Netley? Her Majesty also spoke of the work done by the nursing sisters in connexion with the plague in India and of the distress she felt in reading of the casualties amongst them. Indeed, it would be impossible to convey in words the infinite sympathy and tenderness with which she referred to our troubles in India and to everything connected with our sick and wounded invalids. I $\quad$ am, Sirs, yours faithfully, Surgeon-Major, A M.S.

\section{THE I)IPLOMA OF THE APOTHECARIES'} SOCIETY

\section{To the Elditors of THI LANOET.}

Sins,-With your permission I should like to make a few remarks respecting the late prosecution of a L.S.A. Lond. by the General Medical Council for describing himself as a physician and surgeon. I presume that the proceedings were taken under Sec. 40 of the Medical Act, 1858, for wilfully and falscly pretending to be recognised by law as a physician and surgeon. In 1888 the following letter was pablished in the leading medical journals :-

$$
\text { Society of Apothecaries, London, }
$$

Blackfriars, E.C., Sept. 27th, 1888.

My DEAR SIR,-The title of Surgeon has Iong been in use, implying medical practitioner, but the L.S.A. is a licentiate in surgery as well as in medicine. It cannot be said that he is not a surgeon. It seems to me he may call himself what he likes-physician if he pleases.
F. P. Moles, Esq. T. Plikgrik I, M.D., Secretary.
Yours faithfully.

After such a statement, publicly made and never challenged, I cannot see that a L.S.A. who describes bimself as a physician and surgeon can be said to wilfully and falsely misdescribe himself. I have in perfect good faith described myself as a surgeon for several years and I contend that we are recognised by law as such. Sec. 2 of the Medical Practitioners Act, 1876, says : "All legally qualified medical practitioners, with qualifications in medicine and surgery registered under 'the Medical Act,' shall be capable of being elected surgeons to county infirmaries or hospitals in Ireland.

The regulations for the admigsion of surgeons to the Army say with respect to the candidate: "He must possess two diplomas or licences, recognised by the General Medical Council-one to practise Medicine, and the other Surgery, and must be registered under the Medical Act in force in the United Kingdom at the time of his appointment. A candidate, however, who holds a single diploma from the Society of Apothecaries, obtained under the conditions of the Act of 1886, will be deemed to possess the double qualification required."

If these instances are not recognitions by law as surgeons, I should much like to know what constitutes legal recognition. It would be interesting to learn why the General Medical Council selected a practitioner in an obscure village for prosecution before a bench of magistrates none of whom have probably any special legal knowledge. If the Council in its newly awakened zeal is so anxious to prosecute the men who supply it with its funds, why does it not ride a tilt with some well-known and experienced practitioner Dr. Major Greenwood, honorary secretary of the Brussels Medical Graduates' Association, barrister-at-law, has thrown down the gauntlet. ${ }^{1}$ It must be confessed that the effect of these prosecutions on the public is anything but reassuring, leading them to believe that the L.S.A. is a sort of bogus diploma and its holder a false pretender and a cheat, who is to be hunted down by the General Medical Council, dragged into a police-court and fined, when he attempts to convey to the public a knowledge of the fact that he is a practitioner in medicine and surgery. Meanwhile any ignorant quack without a vestige of medical education may practise with impunity and the Council folds its hands and averts its eyes. I am, Sirs, yours faithfully,

April 18th, 1898. L.S.A. LoND., 1889.

\section{NOTES FROM INDIA}

(From our Special Corkespondent.)

Marked Decline of Mortality from Plague in Bombay.Dissolution of the Plague Committee. - The Discoverer of Plague in Bombay.-Incidents in Plague Work.

Tre past fortnight has seen a remarkably rapid decline in the death-rate for Bombay. Whereas it had reached 135 per 1000 it is now 95 per 1000 . This decline is coincident with, but not necessarily dependent apon, the change of policy with regard to plague measures. There is now an almost entire absence of repressive measures, so that for all practical purposes the epidemic is taking its own course. This course, however, is an apparently natural one and does not appear to have been determined or even modified by 